\title{
Hypodermic Needle
}

National Cancer Institute

\section{Source}

National Cancer Institute. Hypodermic Needle. NCI Thesaurus. Code C73119.

A slender, hollow needle used for injection or aspiration. 